\title{
Paidéia: Management Report - 2019
}

\author{
Paidéia: Relatório de Gestão - 2019 \\ Paidéia: Informe de Administración - 2019
}

\author{
Manoel Antônio dos Santos ${ }^{1}$ (iD \\ Eduardo Name Risk ${ }^{2}$ (iD
}

Scientific editing is a fundamental area of knowledge production whose findings are disseminated mainly in the form of papers, which enjoy the peculiarity of having been assessed by ad hoc consultants, which guarantees a priori their minimum "quality". It is a complex process that does not involve only the direct relationship between author/editor/ reviewer, considering that these are crowded in educational/ research institutions, which, in turn, are under the satellite of research promotion agencies and the science and technology policy of the country. Thus, publishing a scientific journal implies the management of relations between the academic and political-scientific bodies that guide the guidelines of a certain area (Risk, 2010).

The growing concern with the quality of the editorial process is linked to decision-making for different scientific issues with great impact on society, public policies and professional practices (Carvalho, Pianowski, \& Santos, 2019). In this Management Report, we present indicators that give visibility to the editorial management of Paidéia for the year 2019. With the publication of this document, we preserve the tradition of presenting to the scientific community a balance of what the journal has produced in the previous year, making explicit the modus operandi of the processing of the manuscripts in the period. The dissemination of scientific production is backed by a rigorous peer review process. To systematize information relative to the editorial process, it is possible to place the contribution of Paidéia in the contemporary scenario of scientific publications in the Humanities field, particularly Psychology.

\section{Editorial Policy and Arbitration Criteria}

With its first publication in 1991, since 2018 Paidéia has adopted the rolling pass system. Paidéia is affiliated with the Psychology Graduate Program of the Faculdade de Filosofia, Ciências e Letras de Ribeirão Preto at the Universidade de São Paulo (FFCLRP-USP). The Paidéia

\footnotetext{
${ }^{1}$ Universidade de São Paulo, Ribeirão Preto-SP, Brasil

${ }^{2}$ Universidade Federal de São Carlos, São Carlos-SP, Brasil

Correspondence address: Manoel Antônio dos Santos. Universidade de São Paulo. Faculdade de Filosofia, Ciências e Letras de Ribeirão Preto. Departamento de Psicologia. Av. Bandeirantes, 3900, Ribeirão Preto-SP, Brasil, CEP 14.040-901. E-mail: masantos@ffclrp.usp.br
}

journal includes research that addresses a problem clearly related to Psychology, specifically in the areas: Psychology of Health, Developmental Psychology, School and Educational Psychology, Social Psychology and Psychological Evaluation. Paidéia accepts manuscripts based on the different theoretical-methodological approaches acknowledged by Psychology. The published articles should fall into the categories: research report, systematic literature review and theoretical study (submission of these manuscripts is not free, and limited to authors invited by the Editor).

In 2019, Paidéia completed 28 years of existence. Since its founding in August 1991, 30 volumes have been published and its collection is fully available through free access provided by the SciELO collection. The volumes are conspicuous for their diversity and breadth of topics, as well as for the plurality of methodological designs contained in the articles. The editorial line is generalist, considering the theoretical-methodological, epistemological and thematic diversity that pervades the Psychology area.

In terms of the classification in the Qualis Journals system in the area of Psychology (Coordination of Superior Level Staff Improvement / Coordenação de Aperfeiçoamento de Pessoal de Nível Superior, CAPES-Brasil), Paidéia ascended from the B1 stratum, its status until 2011, to A1, the highest-ranking evaluation position, which demonstrates the recognition of the prominent place that the journal occupies within the Brazilian scientific publications.

The prestige given to Paidéia within the scientific community is due to its selective policy of disseminating quality knowledge. Rigorous and thorough assessment is sustained with the support of a highly qualified Editorial Board, structured according to the areas and themes addressed in the articles submitted for consideration. This Council consists of significant names of the academic community, in both the national and international contexts. The processing of the manuscripts is the responsibility of an Editorial Commission composed of Associate Editors. This commission coordinates the rigorous peer review process, by utilizing ad hoc consultants with recognized competence, who have the task of evaluating and improving the manuscripts submitted for consideration.

To consolidate its visibility at the national and international level, Paidéia is indexed in a solid set of national and international databases (or full text portals) 
when compared to the other Brazilian journals in the field of Psychology. Our journal has been indexed in the following databases: SciELO - Scientific Electronic Library Online (FAPESP/BIREME), Scopus (Elsevier), PsycINFO (American Psychological Association), LILACS - Literatura Latino-Americana e do Caribe em Ciências da Saúde (Centro Latino-americano y de Caribe de Informaciones en Ciencias de la Salud), CLASE - Citas Latinoamericanas en Ciências Sociales y Humanidades (Universidad Nacional Autónoma de México), PSICODOC (Colégio Oficial de Psicólogos de Madrid - Universidad Complutense de Madrid), DOAJ Directory of Open Access Journals, Ulrich's International Periodicals Directory, Catálogo Latindex, IRESIE (Universidad Nacional Autónoma de México), Index-Psi Periódicos (CFP/PUCCAMP), Redalyc - Red de Revistas Científicas de América Latina y el Caribe, España y Portugal, Portal de Revistas da USP (Universidade de São Paulo), ProQuest (CSA) - Databases, EBooks and Technology for Research, EBSCO - Information Services, Cengage Learning, Dialnet (Universidad de La Rioja), OAJI - Open Academic Journals Index, Index Copernicus International (IC Journal Master Listt), HINARI - Access to Research in Health Programme, EZB - Electronic Journals Library (Universität Regensburg - Germany), HEAL Link - Hellenic Academic Libraries Link, and Socolar (China Educational Publications Import and Export Corporation - CEPIEC).

The submission of manuscripts is fully computerized through the ScholarOne (Clarivate Analytics) provided by SciELO. The journal adopts a blind review evaluation system, which preserves the anonymity of the authors and reviewers. The texts submitted for consideration must primarily fall within the research report category. In each issue approximately 39 original research articles are published. As part of the new editorial policy of the journal, the Editorial Board decided to invest heavily in attracting articles that give visibility to research results derived from original empirical studies with quantitative or qualitative designs. The potential to make an impact in the area of knowledge is also a criterion for the selection of the manuscripts for publication. To be selected for publication, the manuscripts must be of international interest, rather than just local.

With regard to financing sources, Paidéia has relied on support from financial resources received annually from the Periodical Scientific Publications Support Program of USP (Agência USP de Gestão da Informação Acadêmica - AGUIA) and from the Scientific Publications Support Program of the National Council for Scientific and Technological Development (National Council for Scientific and Technological Development/Conselho Nacional de Pesquisa e Desenvolvimento Científico, CNPq-Brasil), as well as the support of the Graduate Psychology Program of FFCLRP-USP.

The publication standards are included at the end of each issue, which are available online in the languages:
Portuguese, English, and Spanish. Those standards (Instructions to the Authors) are available on the SciELO page (http://www.scielo.br/paideia). The final issue of each volume provides the list of ad hoc evaluators, who contributed to the essential task of reviewing the manuscripts during the year.

Regarding the manuscript arbitration process, Paidéia adopts the mechanism of double-blind review by peers of recognized competence within the scientific community. Thus, the identities of the authors and of the ad hoc consultants are kept in strict confidentiality. The texts submitted for review should be in accordance with the guidelines of the publication standards and may be accepted or rejected by the Editorial Board, based on the recommendations of its members and the ad hoc consultants selected to enhance the evaluation process.

In relation to the availability of the content, Paidéia adopts the Creative Commons License, Attribution Noncommercial CC BY-NC. With this license it is permitted to access, download, copy, print, share, reuse, and distribute the articles, provided it is for noncommercial use and includes the citation of the source, giving appropriate credit to the journal. In such cases, no permission is required from the authors or the publishers.

Another aspect that distinguishes Paidéia in the scenario of Psychology publications is the systematic and periodic provision of information regarding the management process of the journal. In the first issue of each volume/year we publish a Management Report, in which we seek to provide visibility and transparency to the work consolidated in the previous year. This document contains objective indicators to measure the progress of the journal, such as the processing time of the manuscripts, the origin of the authors who have their articles published, and the institutional origins of the reviewers/ad hoc consultants, among other topics of interest (Santos, 2018, 2019). In 2017, Paidéia published a special bilingual (Portuguese and English) supplement dedicated to qualitative methodology articles ${ }^{1}$.

Paidéia has also been featured in the SciELO in Perspective: Humanities (blog) where posts on recently published articles are continuously available. In 2019, the following articles were highlighted: (a) Public Conversations Group as Resource Against LGBT Violence (Souza, Moscheta, \& Scorsolini-Comin, 2019), (b) Latent Structure of Antisocial and Borderline Personality Disorders: A Taxometric Research (Carvalho et al., 2019), (c) Professional Development: Proposition of a Trans-occupational Model from a Qualitative Study (Fernandes, Mourão, \& Gondim, 2019), (d) Practices and Therapeutic Strategies of the Psychosocial Care Centers Alcohol and Drugs (Silva, Abbad, \& Montezano, 2019), (e) Career Success According to New Graduates: Implications for Counseling and Management (Oliveira et al., 2019), (f) Family Dynamics of Boys Victims of Sexual Abuse (Said \& Costa, 2019),

\footnotetext{
${ }^{1}$ Available on the link: https://www.scielo.br/scielo.php?script= sci_issuetoc \&pid=0103-863X20170004 \&lng=pt \&nrm=iso
} 
(g) Evidence of the Validity of the Internal Structure of the Ethical, Transformational and Moral Leadership Scale in an Educational Portuguese Context (Neves \& Coimbra, 2019).

\section{Editorial Process - 2019}

When considering the editorial process of Paidéia in 2019 , it can be observed that the average processing time of the manuscripts was approximately eight months. In this year, the journal received 86 new manuscripts, of which 1 was approved, 70 rejected and 15 were still in the evaluation process in December of 2019 (Table 1).

Table 1

Editorial Situation of the Manuscripts Submitted to Paidéia in 2019

\begin{tabular}{lc}
\hline Final decision & $n$ \\
\hline Approved & 1 \\
Rejected & 70 \\
In the editorial process & 15 \\
Received (Total) & 86 \\
\hline $\begin{array}{l}\text { Note. Mean time between } \\
2019=18 \text { months. }\end{array}$ &
\end{tabular}

Manuscripts submitted in 2019 were classified in the following categories: (a) Research report (91.9\%) and (b) Systematic literature review $(8.1 \%)$, as presented in Table 2.
Table 2

Category of the Manuscripts Submitted to Paidéia in 2019

\begin{tabular}{lcc}
\hline Type of manuscript & $n$ & $\%$ \\
\hline Research report & 79 & 91.9 \\
Systematic literature review & 7 & 8.1 \\
Total & 86 & 100 \\
\hline
\end{tabular}

As presented in Table 3, in 2019, volume 29, 38 articles and 1 systematic literature review were published, as well the management report. The publications were classified into the following categories: (a) Research report (97.4\%) and (b) Systematic literature review (2.6\%).

Table 3

Category of the Manuscripts Published in Paidéia in 2019

\begin{tabular}{lcc}
\hline Type of manuscript & $n$ & $\%$ \\
\hline Research report & 38 & 97.4 \\
Systematic literature review & 1 & 2.6 \\
Total & 39 & 100.0 \\
\hline
\end{tabular}

Figure 1 shows the evolution of the number of manuscripts submitted and their fate in the triennium 2017-2019. These results highlight the rigorous analysis of the manuscripts selected for publication.
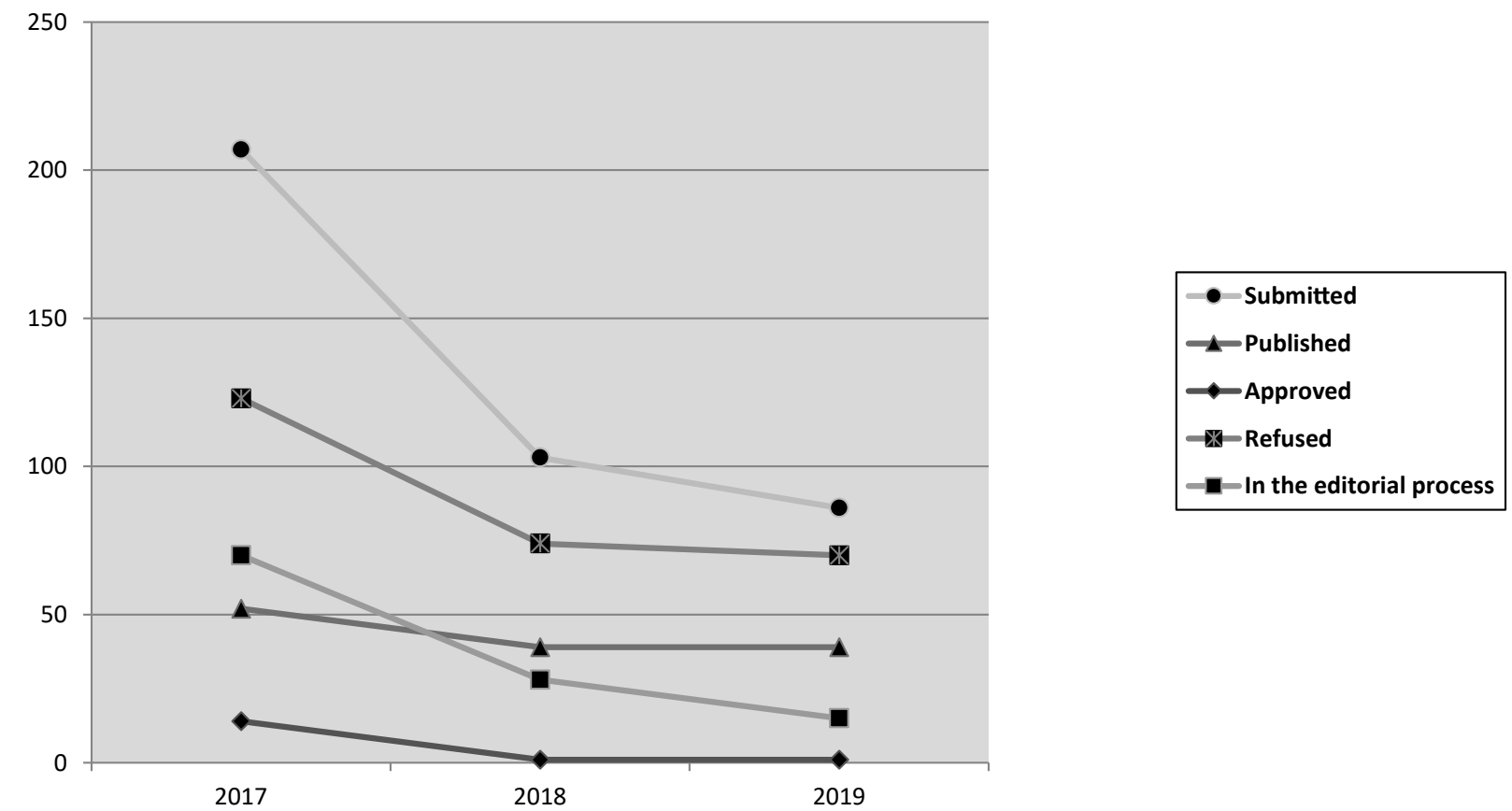

Figure 1. Number of manuscripts submitted to Paidéia and their editorial outcome in the triennium 2017-2019. 
Regarding the institutional affiliation of the authors, Table 4 shows that Paidéia published articles originating from 33 Brazilian universities/colleges/institutes. There was a reasonable increase in the amount of articles with authors affiliated with international institutions, mainly from Portugal and United States (Table 5). It should be noted that the authors of the published articles are linked to a variety of higher education institutions, public, private and confessional, of various states of the Brazilian federation and abroad. In 2019, there was a predominance of federal universities over state ones.

Table 4

National Institutional Origin of the Authors who Published in Paidéia in 2019

\begin{tabular}{|c|c|c|}
\hline National institutions & $n$ & $\%$ \\
\hline Universidade de São Paulo-SP & 11 & 11.5 \\
\hline Universidade Federal de Santa Catarina-SC & 9 & 9.4 \\
\hline Universidade São Francisco-SP & 9 & 9.4 \\
\hline Universidade de Brasília-DF & 6 & 6.24 \\
\hline Universidade Federal do Rio Grande do Sul-RS & 5 & 5.25 \\
\hline Universidade Salgado de Oliveira-RJ & 5 & 5.25 \\
\hline Universidade Estadual de Montes Claros-MG & 4 & 4.20 \\
\hline Universidade Federal da Paraíba-PB & 4 & 4.20 \\
\hline Universidade Federal do Paraná-PR & 4 & 4.20 \\
\hline Pontifícia Universidade Católica do Rio de Janeiro-RJ & 3 & 3.12 \\
\hline Universidade de Fortaleza-CE & 3 & 3.12 \\
\hline Universidade Federal da Bahia-BA & 3 & 3.12 \\
\hline Universidade Federal de São Carlos-SP & 3 & 3.12 \\
\hline Universidade Federal do Pará-PA & 3 & 3.12 \\
\hline Pontifícia Universidade Católica do Rio Grande do Sul-RS & 2 & 2.10 \\
\hline Universidade Estadual Paulista-SP & 2 & 2.10 \\
\hline Universidade Federal de Ciências da Saúde de Porto Alegre-RS & 2 & 2.10 \\
\hline Universidade Federal de Pernambuco-PE & 2 & 2.10 \\
\hline Universidade Tuiuti do Paraná-PR & 2 & 2.10 \\
\hline Centro Universitário de Brasília-DF & 1 & 1.05 \\
\hline Centro Universitário de Maringá-PR & 1 & 1.05 \\
\hline Faculdade Adventista da Bahia-BA & 1 & 1.05 \\
\hline Faculdade INEDI - CESUCA-RS & 1 & 1.05 \\
\hline Fiocruz Bahia-BA & 1 & 1.05 \\
\hline Pontifícia Universidade Católica de Campinas-SP & 1 & 1.05 \\
\hline Universidade do Vale do Rio dos Sinos-RS & 1 & 1.05 \\
\hline Universidade Estadual de Maringá-PR & 1 & 1.05 \\
\hline Universidade Federal do Mato Grosso do Sul-MS & 1 & 1.05 \\
\hline Universidade Federal do Pampa-RS & 1 & 1.05 \\
\hline Universidade Federal do Rio de Janeiro-RJ & 1 & 1.05 \\
\hline Universidade Federal do Triângulo Mineiro-MG & 1 & 1.05 \\
\hline Universidade Federal do Vale do São Francisco & 1 & 1.05 \\
\hline Universidade Paulista & 1 & 1.05 \\
\hline Total & 96 & 100.0 \\
\hline
\end{tabular}


Table 5

International Institutional Origin of the Authors who Published in Paidéia in 2019

\begin{tabular}{lll}
\hline International Institutions & $n$ & $\%$ \\
\hline CIIE - Universidade do Porto, Porto, Portugal & 3 & 15.8 \\
Universidade do Minho, Braga, Portugal & 3 & 15.8 \\
Universidade do Porto, Porto, Portugal & 3 & 15.8 \\
University of Central Florida, Orlando-FL, United States & 2 & 15.8 \\
Pontificia Universidad Javeriana, Cali, Colombia & 2 & 10.5 \\
Université du Québec à Trois-Rivières, Quebec, Canadá & 1 & 10.5 \\
INGENIO (CSIC-UPV), Valencia, Spain & 1 & 5.4 \\
Instituto de Ciências Sociais da Universidade de Lisboa, Lisboa, Portugal & 1 & 5.4 \\
Universidad Nacional de Córdoba, Córdoba, Argentina & 19 & 5.4 \\
Total & 100.0 \\
\hline
\end{tabular}

\section{Final Considerations}

In recent years, Paidéia has worked hard to consolidate itself as one of the most prestigious Psychology publications in the Brazilian context. With true entrepreneurial spirit, coordinated actions have been implemented to create objective conditions for the internationalization of the journal, which enhanced the visibility of the articles published.

This management report systematizes information that permits the mapping of the framework of the editorial processing of the manuscripts submitted to the Paidéia during the year 2019. Comparison of the data accumulated over the last three years shows that the journal has gradually and consistently strengthened its editorial process, establishing itself as a unifying space for the knowledge produced in the field of Psychology. However, some fragilities need to be considered, such as the limited number of international collaborations and the concentration of ad hoc consultants in the Southeastern states. The low percentage of articles from foreign authors is a limitation as well. Overcoming these challenges requires the adoption of specific strategies.

One positive aspect to be highlighted in this report is the adoption of the publication of the full text of the articles in English in 2012, which gives greater international visibility to the articles published in the journal. The journal has ensured its inclusion in new international indexes, which contributes to the internationalization efforts.

Another positive point is that the rate of "endogeneity" of the journal (articles from authors of the Universidade de São Paulo) $11.5 \%$ of the articles published in 2019 although it had a slight increase, remained stable, when considering the historical series. This rate was $7.1 \%$ in 2018 (Santos, 2019), 10.4\% in 2017 (Santos, 2018). In other words, Paidéia proves to be a journal that is truly open to the Brazilian scientific community and, in recent years, increasingly oriented towards the international community.
Regarding the communication of science, it must be remembered that the publication may be through various means, with scientific journals highlighted due to quality control, greater credibility, consistency, and visibility of information. Scientific knowledge is mainly derived from original research, submitted to the peer review process and published in an indexed journal, with attention to the use and impact of the information conveyed. Being indexed in specialized or multidisciplinary databases is the seal of quality of a journal.

Considering the great increase in the national scientific production in recent years, due to a stimulus policy that is unfortunately often confused with the deleterious productivism resulting from the pressure to publish, it is highly desirable for national journals to give greater transparency to their publishing processes. Thus, this Management Report complies with the social mission of returning to society the result of public investments that have been allocated in recent years to the field of science and technology. Finally, the scientific journals play an important role in evaluating the quality and dissemination of the knowledge produced in the area of Psychology. They are the principle means of publication and also the most prestigious and credible.

\section{References}

Carvalho, L. F., Hauck Filho, N., Pianowski, G., \& Muner, L. C. (2019). Latent structure of antisocial and borderline personality disorders: A taxometric research. Paidéia (Ribeirão Preto), 29, e2902. doi:10.1590/1982-4327e2902

Carvalho, L. F., Pianowski, G., \& Santos, M. A. (2019). Guidelines for conducting and publishing systematic reviews in Psychology. Estudos de Psicologia (Campinas), 36, e180144. doi:10.1590/1982-0275201936e180144 
Fernandes, H. A., Mourão, L., \& Gondim, S. M. G. (2019). Professional development: Proposition of a transoccupational model from a qualitative study. Paidéia (Ribeirão Preto), 29, e2916. doi:10.1590/1982-4327e2916

Neves, L. G., \& Coimbra, J. L. (2019). Evidence of the validity of the internal structure of the Ethical, Transformational and Moral Leadership Scale in an educational portuguese context. Paidéia (Ribeirão Preto), 29, e2904. doi:10.1590/1982-4327e2904

Oliveira, M. C., Melo-Silva, L. L., Taveira, M. C., \& Postigo, F. L. J. (2019). Career success according to new graduates: Implications for counseling and management. Paidéia (Ribeirão Preto), 29, e2913. doi:10.1590/1982-4327e2913

Risk, E. N. (2010). A editoração científica em questão: Dimensões da Psicologia [Scientific editing in question: Psychology dimensions]. Revista Brasileira de Orientação Profissional, 11(1), 151-153.

Said, A. P., \& Costa, L. F. (2019). Family dynamics of boys victims of sexual abuse. Paidéia (Ribeirão Preto), 29, e2908. doi:10.1590/1982-4327e2908

Santos, M. A. (2018). Paidéia: Management report - 2017. Paidéia (Ribeirão Preto), 28, e2801. doi:10.1590/ $1982-4327 \mathrm{e} 2801$

Santos, M. A. (2019). Paidéia: Management report - 2018. Paidéia (Ribeirão Preto), 29, e2940. doi:10.1590/ $1982-4327 \mathrm{e} 2940$

Silva, M. N. R. M. O., Abbad, G. S., \& Montezano, L. (2019). Practices and therapeutic strategies of the psychosocial care centers alcohol and drugs. Paidéia (Ribeirão Preto), 29, e2903. doi:10.1590/1982-4327e2903

Souza, L. V., Moscheta, M. S., \& Scorsolini-Comin, F. (2019). Public conversations group as resource against LGBT violence. Paidéia (Ribeirão Preto), 29, e2905. doi:10.1590/1982-4327e2905

Manoel Antônio dos Santos is an Full Professor of the Faculdade de Filosofia, Ciências e Letras de Ribeirão Preto at the Universidade de São Paulo, Ribeirão Preto-SP, Brasil and Editor Responsible of Paidéia (Ribeirão Preto).

Eduardo Name Risk is an Assistant Professor of Departamento de Psicologia from Centro de Educação e Ciências Humanas at the Universidade Federal de São Carlos, São Carlos-SP, Brasil, and Assistant Editor of Paidéia (Ribeirão Preto).

How to cite:

Santos, M. A., \& Risk, E. N. (2020). Paidéia: Management report - 2019. Paidéia (Ribeirão Preto), 30, e3001. doi:10.1590/1982-4327e3001 